\title{
Legal Concerns with Academic Engagement Programs in Developing Countries
}

\author{
Molly Eckman, Ellie Kriner, \\ Khanjan Mehta \\ Humanitarian Engineering and Social \\ Entrepreneurship (HESE) Program \\ The Pennsylvania State University \\ Correspondence: khanjan@engr.psu.edu
}

\author{
Kevin Prucino, Meng Lian, \\ Xiling Tang, Jeffrey Erickson \\ Penn State Law \\ The Pennsylvania State University
}

\begin{abstract}
Universities and other institutions of higher learning have seen an increase in the number of academic programs that involve engagement with external communities, especially in the developing world. These programs may include travel abroad, community service, or the design and commercialization of new products. Despite this growth, many faculty and program leaders remain unaware of the legal concerns and challenges that might arise on these types of activities. This article informs faculty on the legal nuances relevant to different types of academic engagement programs. Representative examples of each type of program are used to illustrate legal concerns that may arise, and compromise academic engagement programs.
\end{abstract}

Index Terms - student engagement, legal challenges, developing world

\section{INTRODUCTION}

Over the past few decades, there has been an increase in academic programs that engage with external communities through activities such as travel abroad, community-based service projects, design-build projects or the development and commercialization of new technologies. These engagements requires adherence to a host of legal regulations that may be unfamiliar to the program coordinators.

Programs that do not adhere to relevant legal requirements risk serious legal and public relations ramifications. Academic enrichment programs hold the unique position of being both great assets to a university's reputation while simultaneously increasing risk. Injury, damages, and lawsuits resulting from a program can result in significant financial cost to the university. Risk management departments are responsible for overseeing and mitigating these types of risks. In addition, these types of incidents may damage the university's image. In many ways, a university is like a business in that it must cultivate and maintain a brand or reputation. Academic institutions build their reputation and increase their prestige though supporting innovative programs and research, hiring distinguished faculty, and promoting successes through the media. A large amount of energy is spent protecting this image, and most universities have strategic communications offices dedicated to this cause. This is especially true in the era of 
social media, where news travels extremely quickly. However, despite these risks, universities tend to utilize academic enrichment programs to enhance their reputation as innovative leaders.

The concepts introduced in this article are not novel but rather commonplace in the legal world; however, they are presented here in conjunction with examples and applications to form a practical introduction for faculty engaged in international scholarship activities. A typology of engagement programs is presented and the legal concerns for each type are explored with the help of illustrative examples.

\section{TYPOLOGY OF ENGAGEMENT PROGRAMS}

Many types of academic and co-curricular programs engage with local and global communities. These programs include academic courses with embedded travel components, alternative spring break programs, and international service trips. The goals, methodologies, and philosophies of these programs may vary from week-long volunteering experiences, with goals of immediate impact, to multi-year ventures, with philosophies of sustainability and scalability. However, most can be grouped into one of three categories depending on what is left behind at the culmination of the program: education, infrastructure, products, or business ventures. Programs in these categories often differ in the amount of time spent on the ground, level of involvement of the local community, and the desired outcome once the academic program has completed its involvement. Some programs may fall within multiple categories.

\section{Knowledge transfer programs}

Knowledge transfer programs aim to educate the local community on a topic relevant to them. This may take the form of teaching children math and science, holding workshops to improve job skills, and educating farmers on more effective harvesting practices. These programs are generally characterized by high levels of community involvement for the duration of the program, though there is minimal activity afterwards. Impact takes the form of basic knowledge shared and capacity-building, which can be leveraged to improve livelihoods. Program philosophies tend to have strong service missions and value volunteer work.

In this type of engagement program the transfer of knowledge may be bidirectional between participating students and the community. Students teach academic subjects such as English or math, but they experientially learn about local culture and customs. The level of interaction with the community can vary from one venture to another, however, interactions generally occur in a very informal manner. This informality is primarily a result of the transient nature of these programs. Formal, long-term agreements are generally not necessary as community-student interaction ends with the culmination of the program.

\section{Building and infrastructure Programs}

A common engagement program is one that involves the construction of buildings or other infrastructure such as bridges, water systems, or farm animal housing. Student involvement is often confined to construction, though some programs may require the students to design the structures they build. Long-term performance of the structures built is rarely assessed; instead, maintenance and upkeep is relegated to the local community.

Community members are often recruited to aid in construction, though they may not be officially employed. In many instances, these individuals will have more experience than the 
students and are able to teach students the necessary skills. Because most of these programs are often shorter, standalone trips, relationships with the local communities may be informal and short-lived.

\section{Product design programs}

Often more technical in nature, product design programs are characterized by the creation of context-appropriate devices. Community involvement is often reduced in these programs, as the primary challenges are technical and not social in nature. Fieldwork may consist of testing and implementing novel designs or may focus solely on distribution. For example, students may spend a semester designing a low-cost water filtration device and subsequently travel to the target region to further test and distribute the product. Long-term assessment methods may be used to track product progress and use after the culmination of the fieldwork experience, though this is not always the rule.

Interactions with community members take the form of training sessions on the operation of the product, opinion surveys as to the effectiveness of the product, or side-by-side manufacture work. Since the goal of product design programs is for the product to remain in use after the culmination of the fieldwork experience, more formal relationships are required to ensure that standards are upheld in the absence of program supervision. In addition, the development of new products requires an understanding of legal regulations in the region.

\section{Entrepreneurial programs}

Entrepreneurial engagement programs share the goal of creating sustainable and scalable enterprises. Often these ventures are social in nature. For instance, a business manufacturing, marketing and selling low-cost greenhouses may be developed with the goal to address food security issues. Students spend time designing new products or services as well as the accompanying business models and execution strategies. Time on the ground is spent forming partnerships, identifying champions, evaluating business strategies, conducting market research, and planning for how the venture will function after the culmination of the program.

Community involvement is much more critical to these types of programs because it is ultimately the community who will be responsible for the success or failure of the ventures. In order to make a project more sustainable it is crucial that the community play a part in the design, implementation, and long-term strategy. This practice is especially important for these types of programs because the community also makes up the target market, and market research is essential to the success of an entrepreneurial venture. Often these ventures span several years, requiring long-term partnerships and substantial funding sources. In addition, the profitgenerating nature of these businesses often attracts more community and government attention.

\section{LEGAL CONCERNS OF ENGAGEMENT PROGRAMS}

Each of these types of programs faces a unique set of legal challenges (Table 1). Faculty leads of successful programs must be aware of potential legal requirements specific to the relevant type. While the specific challenges may vary from program to program, they generally fall into one of three categories: regulatory, ownership, and liability. 
TABLE 1

SUMMARY OF LEGAL CHALLENGES

\begin{tabular}{|c|c|c|c|}
\hline Program type & Regulatory & Ownership & Liability \\
\hline Educational & Local rules & -- & Compliance \\
\hline $\begin{array}{l}\text { Building and } \\
\text { infrastructure }\end{array}$ & $\begin{array}{l}\text { Building codes, approvals, } \\
\text { inspections, licenses, local } \\
\text { ordinances }\end{array}$ & Property law & Tort law \\
\hline Product design & Product regulations & $\begin{array}{l}\text { Obtaining, transferring } \\
\text { intellectual property }\end{array}$ & $\begin{array}{l}\text { Tort law, warranties } \\
\text { (contracts) }\end{array}$ \\
\hline Entrepreneurial & $\begin{array}{l}\text { Entity formation and } \\
\text { operation }\end{array}$ & $\begin{array}{l}\text { Obtaining, transferring } \\
\text { intellectual property rights }\end{array}$ & $\begin{array}{c}\text { Compliance } \\
\text { (employment, taxation), } \\
\text { tort law, contracts }\end{array}$ \\
\hline
\end{tabular}

Regulatory challenges include standards and approvals that must be adhered to when creating something. Building codes provide the design requirements of any type of infrastructure to ensure public safety, such as load requirements, material properties, fire hazards, and more. ${ }^{1}$ Product regulations detail similar requirements but relate to consumer goods. Entity formation is the registration a new business or other organization with the local government. This process varies based on the type of business entity being created, and each country has its own list of entity categories such as corporations, partnerships, and cooperatives. Once an entity is established, it has an ongoing duty to comply with regulations that require it to keep accurate books, file reports, abide by employment laws, and so on. ${ }^{2}$

Ownership laws determine a party's rights and duties relating to areal or intellectual property. Property laws detail who owns and may use land, and for what purpose. Intellectual property laws demarcate ownership of ideas and innovations, providing protection from unwanted copying or selling of these ideas. Entrepreneurial ventures may use licensing agreements to transfer their intellectual property for use by other parties.

Liability remains a prominent concern for all programs. Liability, broadly defined, is a party's responsibility for its actions: More than merely the typical personal injury tort case, liability would include responsibility for breach of contract, for non-compliance with regulations, etc. Tort liability is responsibility for damages or injury caused by a party's wrongful act. The offending party may then be forced to pay damages as reparations for injuries or other wrongs. Torts include injuries caused to people and to property, both real and intellectual. Thus, torts include causes of action ranging from negligence, to trademark infringement, to product liability, to defamation. ${ }^{3}$

Contracts can be broadly defined as agreements made between two or more parties. Often they define terms of compensation and quality in the exchange of goods or services rendered. Contracts vary widely in degrees of formality, and the type and content of a contract are determined by the specifics of the location, culture, local regulations, and purpose. ${ }^{4}$ Different types of contracts may be needed in different situations. A common situation requiring a contract 
is the employment of local labor to sustain or aid the academic program. This could include hiring manual labor to build a greenhouse for testing or employing health workers in a social enterprise. A short-term building and infrastructure program may only require a work for hire to build a single structure, but an entrepreneurial program may want to draw up an employment contract to form a long-term relationship with the employee. Vendor contracts may be needed to secure necessary supplies or services. Product warranties are contracts (which may be express or implied) that guarantee the quality of a product to a consumer and may include the offer of repair or replacement of a defective product. ${ }^{5}$

An informal contract, such as one needed for a short-term program that involves low-cost work-for-hire, may not need to be written down. For example, the hire of a local who happens to own a vehicle for a one-time delivery of materials to build a greenhouse might not require a formal written contract. More formal contracts dealing with long-term partnerships or exchanges of larger sums of money must be written and signed by all involved parties. For example, a group may desire to analyze soil in Kenya by collecting samples and sending them to an external lab. A service contract specifying the cost per sample, time allotment for analysis, and method of reporting findings would formalize the agreement and help avoid miscommunications. In many developing regions, especially where literacy rates are low, written contracts are not trusted ${ }^{6,7}$. In this case, verbal agreements based on trust among parties might substitute. Verbal agreements can also serve as the basis of breach of contract claim.

Licensing agreements may be used to transfer intellectual property from one entity to another. Incidentally, contracts may be used to allocate liability between parties prior to an incident occurring: for example, an entity may require that a licensee producing a licensed product bear financial responsibility and indemnify the entity for any harm that results from sale of the licensed product. Confidential information may be protected through the use of nondisclosure agreements (NDAs).

A memorandum of understanding (MoU) (also known as a letter of intent in the United States) is similar to other types of contracts in that it outlines the parties involved, purpose and scope of the agreement to be made, duration of the agreement, and other important factors. ${ }^{8}$ However, a MoU is generally not legally binding, but is an expression of the goodwill between the parties and the aspiration of their cooperation.

\section{Legal concerns of knowledge transfer programs}

Since knowledge transfer programs do not leave behind any type of physical object that may cause harm or need ongoing maintenance, these programs face few legal challenges. The primary concern is liability for compliance with local regulations. Many developing nations have specific policies and stances that foreign educators must adhere to. Teaching licenses often require teachers to provide accurate and reliable information.

For example, a group of students may travel to Sierra Leone for a week to hold group classes on HIV/AIDS prevention. The government in Sierra Leone advocates for a longer breast feeding duration than the students intend to recommend. However, the students should not contradict local policies and may need to revise their curriculum in that light. The students should be very diligent about the information they share. 
Legal concerns of building and infrastructure programs

Faculty planning on leading a building and infrastructure program must be aware of the relevant building code, applicable property law, tort law and contract law of their target country and region. Most countries will require any constructions to meet predetermined standards, such as environmental restrictions and technical design requirements. Detailed information about building and infrastructure regulations are usually described in the locally accepted building code.

During the construction phase, faculty of the university may find it useful to enter into contracts with material suppliers or land owners in order to formalize these relationships. Any controversies that may arise, such as disputes over pricing, delivery, or quality, may be resolved by adhering to the stipulations of the contract. Ownership of the building or infrastructure must be also be determined. Most of the time, this determination is made by the local property law and government regulations. In addition, liability for the building should be allocated. If not properly accounted for, the university may be found responsible for any damages caused by the building or infrastructure. In some cases, the owners of the land and the owners or operators of the building may not be the same people.

As an example, consider a weeklong, faculty-led trip to build a bridge in a small village in Sub-Saharan Africa. The bridge could be a simple foot bridge intended only for pedestrians, or it may be a complicated structure designed for vehicle use. Before building the bridge, there are two factors that need to be considered: the easement, which is the right to use another's land for a specified purpose, and the license of the leading engineer. The land license guarantees the legitimacy of the construction. In the case of a foot bridge, the project may be small and informal enough to preclude the need for a license. However, the larger vehicle bridge would require considerable amounts of land and a longer construction period, and it would therefore be best to check the status of the land and request a building permit. Regardless of the type of bridge, this program will require the involvement of a licensed engineer responsible for the design of the bridge. In an academic program such as this one, the lead engineer will generally be the faculty leading the program. Some countries may not allow foreign engineers to work independently, and instead may require collaboration with local engineers.

During the construction, the group may need to purchase materials, such as concrete or lumber, locally. To ensure the quality of the materials, the program should sign a contract with the local supplier stipulating consequences and liability allocation in the case of bridge failure due to poor materials. The program could also work with contactors who would have their own warranty for the quality of their materials, which would transfer liability to them if these materials were faulty. An easement contract with the owner of the surrounding land may be necessary if temporary use of this land is crucial to the success of the project. This type of contract gives a party the rights to enter of use an area of land without the owner actually transferring ownership.

In preparation for the completion of the bridge, two concerns must be addressed: ownership and maintenance. The foot bridge may simply be given to the public for general use. Maintenance responsibilities would then fall to those who use the bridge. The vehicle bridge, on the other hand, must have a formal declaration of ownership due to its size and complexity. Generally, the bridge will be the property of whomever owns the land and hence the owner is determined during the acquisition of the land license. However, property laws may vary from country to country. If the target country separates the right of land from the right of building, 
then local legislation must be consulted. Maintenance in this case is usually provided by the owner. Both ownership and maintenance are critical issue for the vehicle bridge, as both the value added by the bridge and the maintenance costs are significant.

Finally, before the project is completed, it must be decided who is financially responsible for all or part of the project in the case of bridge failure or collapse. Financial responsibility is primarily determined by the nature of the failure. If the collapse was due to poor-quality material, liability is allocated based on the terms of the contract made with the supplier. If the collapse was caused by a poor design, the engineers behind the plan may be found liable. If the collapse was a consequence of an unexpected natural disaster, all parties could be exempt from liability. The use of indemnification clauses in contracts made during the engagement will help the different parties in the engagement allocate financial responsibility at the onset of their relationship. Damages that the liable party may be responsible for include both property loss and personal injury caused by the bridge failure.

\section{Legal concerns of product design programs}

Designing and distributing products internationally presents several unique legal challenges. Some general concerns may include product regulation, intellectual property, warranty, and product liability. The faculty, students, or university involved in developing a product may want to protect their intellectual property, which could include the product design or brand. It should be noted that in many contexts, this protection may not practically be available as many countries in the developing world do not enforce intellectual property laws. When a product is put into the market, product warranties can be used to guarantee the quality of a product to a consumer as well as offer repairs or replacements of defective products. If a product causes harm, any party involved in the creation of the product, including the university, may be liable for damages.

Many universities have programs focused on designing products to address problems in the developing world. To illustrate the legal obstacles faced by these programs, consider an engineering design course in which a student team has designed and manufactured a water purification system for use in resource-constrained settings. In one case, the students may travel abroad to teach residents of these areas how to manufacture the devices themselves. Alternatively, they may choose to mass-produce the filter for distribution on a larger scale. While both types of products and approaches could invoke legal concerns, the standardized massproduced products are more likely to require significant legal planning.

Before either purifier product is put into use, the team must research the relevant regulations of the target country. Each country has a drinking water quality standard that should guide product design. In both cases, the purifier design must meet the applicable local regulations, which outline acceptable material, safety parameters, and more. These regulations are determined by specific governmental agencies. For example, the Food and Drug Administration (FDA) in the United States determines standards for pharmaceuticals and food products, while the Kenyan Bureau of Standards (KEBS) sets quality standards for all products in Kenya. For purifiers intended to be distributed to multiple countries, each country's regulations as well as import and export laws must be adhered to. The International Organization for Standardization is an independent, non-governmental organization that creates product standards that many nations adopt, and may serve as a guideline if local regulations are absent or difficult to find. ${ }^{9}$ The product should be designed to meet the most stringent regulations that may apply in the intended region of distribution. 
In the developing world, intellectual property rights are often poorly enforced. ${ }^{10,11}$ In the case of the locally manufactured purifier, it may not be necessary to patent the design. On the other hand, because of the larger distribution area of the mass-produced filter, the designer may wish to patent the design and register trademarks such as a brand name and logo. This process may protect the design and brand from appropriation by others, which may also help establish a trusted brand identity. Despite the poor enforcement of intellectual property laws, it is important to determine whether the designer has the freedom to operate in the target country; that is, whether the product infringes on any intellectual property established in that region. This determination is dependent on location, as intellectual property laws and patents can vary from country to country.

After a product is distributed to end-users, the product may be subject to an implied warranty of merchantability or an implied warranty of fitness for a particular purpose. Therefore, even if the product doesn't come with an express warranty, the manufacturer or seller may legally be required to replace or repair a product that did not perform as expected, or provide some other remedy. For the locally manufactured purifier, this may mean that a local buyer returns to the manufacturer, likely a known community member, and they deal with the issue informally. In the case of the mass-produced purifier, the manufacturer or seller will have to abide by applicable warranty law. It is conceivable that actually providing a written warranty could be preferable in risk management, as it may allow certain limitations to the warranty. This should be considered for any mass produced product.

Product liability generally arises in one of two ways. The most common product liability is based on the use of a defective product. For example, if the purifier has design or manufacturing defect and it makes people sick, the manufacturer would be liable for damages. The second type is known as marketing defects. If the manufacturer or seller fails to warn a buyer that a purifier cannot be used with hot water, and someone subsequently is harmed because hot water was used and deactivated purification, the manufacturer might be liable for resulting damages. For any product that either is complex to operate or by its nature poses significant risk if used incorrectly (e.g., a water purifier), extreme care should be given both to instructions and written warranty information.

Product design programs must necessarily consider tort liability and insurance coverage. Although many tort causes of action are premised on a party's negligence, defective products are subject to strict product liability. In other words, a distributor or manufacturer of a defective product is liable to an injured party regardless of whether they were negligent or entirely reasonable in ensuring the safety of the product.

These examples illustrate some of the many potential legal concerns that may arise in developing products. During the product design phase, designers will want to consider regulatory schemes, how intellectual property rights are handled in the target country, what their potential liabilities are, and what actions may be taken to insure against such liabilities.

\section{Legal concerns of entrepreneurial programs}

An entrepreneurial engagement typically involves three general areas of law: entity formation and operation, trade, and taxation. When developing a business model for an entrepreneurial engagement the ways that these areas of law apply in your engagement should be assessed. One of the first steps in an entrepreneurial project may be to create a brand new business entity in the host country to carry out the engagement. Different countries have different types of business 
entities, though most countries recognize similar forms such as corporations, partnerships, and cooperatives. This allows the business entity to absorb liability, properly employ individuals, and pay taxes. If the engagement sells goods across country lines, international trade law will be implicated. Taxation will be a concern because the engagement will typically be taxed in some way, whether on the property, the income, and/or the assets.

An engagement team could always encounter other areas on law in an entrepreneurial engagement. For example, intellectual property laws that apply in the country may be implicated when dealing with patents, logos, and products. If a business entity is created in the host country under the name of the humanitarian institution, this ownership will need to be transferred when the project is finally "handed off". Additionally, a non-disclosure agreement may be appropriate if there are concerns of confidentiality with the engagement. Non-disclosure agreements and ownership transfer would be licensing issues that would be controlled by contract law. Generally, these areas of law are not as common of a concern as entity formation and operation, trade, and taxation for entrepreneurial engagements, but the possibilities are worth consideration.

Entrepreneurial engagements can differ greatly in their level of formality. A solar charging station for a village is an example of a small scale informal entrepreneurial engagement. The charging station converts solar energy into electricity so that the people in the village can charge electrical devices like cellular phones for a small price. The station and business model is handed over to a local who becomes the owner and operator of the station. The owner then employs a very small number of employees who work their respective shifts when the owner is not there. The engagement generates revenue, creates a small number of jobs, and provides a valuable service for locals.

An example of a larger scale, more formal entrepreneurial program would be a venture that builds and sells affordable greenhouses in the developing world. The student team has developed an inexpensive greenhouse that can be easily constructed with materials that are accessible in the host region. They may decide to license the design to an external company. This company then sells the greenhouse materials to contractors who build the greenhouses for private parties. In this scenario the company is functioning as a hub that creates opportunities for employment within the company itself and the contracting companies in addition to providing a cost effective greenhouse to the public.

In an informal engagement like the charging station the engagement team may need to assist the new owner of the station in creating a business entity. Forming the business entity would allow the station to have the abilities and protections of corporations in that country and may even be required before generating revenue and employing individuals. With the more formal greenhouse venture the humanitarian team is working with a company who is already a business entity, therefore, formation of a business entity would not be an issue. However, if a new partner is joining the greenhouse venture company as part of the engagement, entity formation and operation may be implicated. A new entity including the partner may need to be formed or the partnership terms may need to be modified.

When the charging station is operating, it will be generating revenue; and where profits are being made the government will want to tax income. Even a small scale charging station may have to conform to local tax laws requiring proper reporting, keeping necessary business records, and payment. In addition, it may be necessary make sure the charging station venture is complying with employment requirements in the area. Depending on the formality, the charging station may be subject to employment laws with respect to vacation/sick/maternity time, 
worker's compensation, age requirements, hours and wage requirements, etc. Being fair to employees is an ethical obligation.

The greenhouse venture would likely have larger concerns with taxation during ongoing operation because of the formality of the operation and larger amount of revenue, employees, and assets. Similarly, employment laws must be adhered to, likely on a much greater scale than the charging station. If the venture decides to sell its greenhouses across national boundaries, international trade law may be implicated. A vendor may be needed to supply a specific type of lumber or a regular means of transportation. Vendor contracts stipulate how long the service will be provided, standards for the service, liability agreements, and payment methods.

\section{CONCLUSION}

The growth of academic enrichment programs in international settings demands an equivalent growth in awareness of the possible legal implications associated with such programs. A clear understanding of the basic legal concepts that could pertain to the program and how these legal concepts apply are crucial to the success of any engagement program. Legal pitfalls vary from program to program, so understanding which concepts are applicable to which situations is useful and can help academic enrichment programs avoid unnecessary pitfalls that could damage the parent institutions' reputation or incur unnecessary costs. As outsiders, humanitarian engagement teams are at a disadvantage. If possible, one should consult a local to guide for advice. Ultimately it will up to the engineers, global health workers, and entrepreneurs (and their institution's risk managers, general counsel, and communications department) to determine whether to abide by the letter of the law or practicalities in the field. Generally, it is sensible to walk the line by complying with the letter of the law wherever possible, complying with local custom and tradition in any case, and most importantly always acting within ethical bounds.

\section{REFERENCES}

${ }^{1}$ FEMA. (2015). Building Codes. Retrieved from Plan, Prepare, and Mitigate: http://www.fema.gov/building-codes

${ }^{2}$ Hunt Law Group. (2015). Entity Formation. Retrieved from Hunt Law: http://www.huntlawgrp.com/corporate-law/entity-formation

${ }^{3}$ Goldberg, J. C., \& Zipursky, B. C. (2013). Tort Law and Responsibility. In Philosophical Foundations of the Law of Torts.

${ }^{4}$ Cornell University Law School. (2015). Contract. Retrieved from Legal Information Institute: https://www.law.cornell.edu/wex/contract

${ }^{5}$ Blischke, W. R., \& Murthy, D. N. (1992). Product warranty management-I: A taxonomy for warranty policies. European Journal of Operational Research, 62(2), 127-148.

${ }^{6}$ Bell, C., Dzombak, R., Sulewski, T., \& Mehta, K. (2012). Preparing and Complying with Institutional Review Board Protocols for Integrated Research and Entrepreneurship Ventures in Developing Countries. Journal of Ethics \& Entrepreneurship, 2(1), 21-35. 
${ }^{7}$ Harding, A., Harper, B., Stone, D., O'Neill, C., \& Berger, P. (2011). Conducting research with tribal communities: sovereignty, ethics, and data-sharing issues. Environmental Health Perspectives, 6-10.

${ }^{8}$ United States Department of Justice. (2008). Sample Memorandum of Understanding. Retrieved from http://www.justice.gov/sites/default/files/ovw/legacy/2008/10/21/samplemou.pdf

${ }^{9}$ International Organization for Standardization. (2015). About ISO. Retrieved from ISO: http://www.iso.org/iso/home/about.htm

${ }^{10}$ Goldberg, P. K. (2010). Intellectual property rights protection in developing countries: the case of pharmaceuticals. Journal of the European Economic Association, 8(2-3), 326353.

${ }^{11}$ ICTSD Programme on Intellectual Property Rights and Sustainable Development. (2009). The Global Debate on the Enforcement of Intellectual Property Rights and Developing Countries. Geneva: International Centre for Trade and Sustainable Development. 